\title{
Effect of Linear and Non-Linear Estimation of Fish Mortality on Feed Conversion Rate and Economic Profitability of Oreochromis shiranus in Cages
}

\author{
Phiri Francis ${ }^{1,2 *}$, Singini Wales ${ }^{2}$, Kapute Fanuel ${ }^{2}$ and Jere Bob ${ }^{2}$ \\ ${ }^{1}$ Department of Fisheries, Chisitu Fisheries Research Station, Africa \\ ${ }^{2}$ Department of Fisheries and Aquatic Sciences, Mzuzu University, Africa \\ Submission: July 27, 2018; Published: August 24, 2018 \\ "Corresponding author: Phiri Francis, Department of Fisheries, Chisitu Fisheries Research Station, Chisitu, Mulanje, Malawi, Africa, Po Box: 105, \\ Tel: +265888358737/+265999606727, Email: phraphiri@yahoo.co.uk
}

\begin{abstract}
This study was conducted to investigate the effect of linear and non-linear methods of estimating fish mortality on feed conversion ratio (FCR) and profitability of cage cultured Oreochromis shiranus (Makumba). Two treatments were used, designated as $\mathrm{T}_{1}$ and $\mathrm{T}_{2}$ and were replicated three times. In each cage, 105000 fish were stocked at an initial average body weight of $1.59 \pm 0.04 \mathrm{~g}$ and cultured for 365 days. The fish was fed twice a day with formulated feed (36\% Crude Protein) at 4-1\% body weight with feed adjustments based on standing biomass from linear and non-linear estimated mortality. The results showed that there were significant differences between the two treatments on FCR $\left(z^{2}=0.003\right)$. Final mean weight was $179.41 \pm 7.71 \mathrm{~g}$ and feed conversion ratio was $1.64 \pm 0.15$ for $\mathrm{T}_{1}$ and $177.56 \pm 8.27 \mathrm{~g}$ and $1.54 \pm 0.14$ respectively for $\mathrm{T}_{2}$. Profitability of the two treatments was calculated by enterprise budgeting. There were significant effects on gross margin between the two treatments Gross margin values were $\mathrm{K} 302,523,924.30$ for $\mathrm{T}_{1}$ and $\mathrm{K} 356,065,320.29$ for $\mathrm{T}_{2}$. The study concludes that use of non-linear method of estimating fish mortality affect feed conversion ratio and economic profitability of Oreochromis shiranus cultured in cages. It is therefore recommended to use non-linear method of estimating fish mortality if farmers are to reduce FCR and maximize profits from the cage culture of Oreochromis shiranus as feed wastage due to feed overestimation resulting from miscalculation of mortality, can be minimized by $15.77 \%$.
\end{abstract}

Keywords: Feed conversion ratio, Profitability, Linear, Non-linear, Mortality, Oreochromis shiranus

\section{Introduction}

Fish catches in Malawi's natural waters have experienced a sharp decline over the past decades, and as reported by Morgan in [1] sustainability of the fish stocks is not likely, given the demand for fish in the country. This development contributed to the increased emphasis on developing aquaculture as a major source of fish and rural income. Aquaculture now occupies a strategic position in the fisheries sector in Malawi. Development of a viable and sustainable cage aquaculture industry has therefore been identified by the Government of Malawi (GoM) as a flagship programme [2]. According to Balarin \& Haller as reported [3] fish growth in aquaculture is a result of several factors such as proper doses of fertilizer application, regular feeding, optimum stocking density, maintenance of physicochemical factors, disease prevention and various control measures. The success of cage culture production as in all forms of aquaculture systems is therefore dependent on fish survival rate and how fast the fish grows to table size with reduced production inputs. Fish like any other living organism undergo several life series events among which growth and risks to life are. Fish in its lifetime is exposed to and must overcome several risks including: predation, starvation, disease and theft, all of which result into fish mortality [4]. Fish losses in cage culture come about due to death (mortality) escapes and theft. According to [5] fish can die at any time within the culture period, but small fish are more vulnerable to cannibalism, bird predation, water quality imbalance, and disease than larger fish. This means that majority of the mortality occurs in small fish as compared to bigger fish. Fish mortality rate (MR) is often established using the estimated numbers method by use of historic records [6]. This can be expressed as linear and non-linear method of estimating mortality. In Malawi, like with most farmers in the region, fish mortality is estimated using linear method, where it is assumed that fish die at a constant rate along the production cycle. However, in non-linear estimation method, mortality is high at juvenile stage and almost insignificant at adult stage/ table size. As reported by [6] feed requirements are calculated based on estimated standing biomass in the cage. This biomass is determined taking into account mortality levels along the production period. Most Malawian farmers using the estimated numbers method, experience a $30 \%$ mortality rate in their cages.

Use of enough feeds that can be fully ingested and utilized by the fish is of paramount importance in commercial as well as small scale aquaculture. Feed wastage through application of excess feed based on poor stock assessment or cage biomass 
projections has contributed to loss of feed and consequently high production costs. The key challenge has been, and continue to be poor estimation of fish feed, which is caused by miscalculation of mortality or fish loss which in turn affect feed conversion ratios as well as farm economic performance. Over-estimation of feed emanating from underestimation of fish mortality can result in higher FCR values, while under-estimation of feed from overestimation of fish mortality results into unrealistic FCR values. Most farmers in Malawi use linear estimation of fish mortality, where mortality is believed to occur throughout the culture period at a constant loss-rate. Use of linear estimation method can bring over-estimation of the standing-crop biomass hence an over-estimation of feed during calculation of feed rations, resulting into high feed conversion ratios. This is counterproductive and can lead to abandonment of fish culture due to high economic losses. The present study used FCR in analysing productivity due to its direct linkage and capacity to estimate feed (input) potential in attaining fish growth (output). The study also used gross margin analysis to assess profitability potential of the mortality estimation methods since gross margin use variable costs to estimate the profitability prospect of an enterprise against its revenues by looking at whether an enterprise will cover its production costs. Therefore, the aim of the study was to investigate the effect of linear and non-linear estimation of fish mortality on feed utilisation and economic performance of Oreochromis shiranus in cages.

\section{Materials and Methods}

\section{Area of study}

The study was conducted between December 2011, and January 2013 at the Malawi Development Corporation (MALDECO) Aquaculture Ltd in Mangochi District, Southern Malawi Figure 1. MALDECO lies at a latitude of 19⒚982'S, and a longitude of $35^{\circ} 09.149^{\prime} \mathrm{E}$.

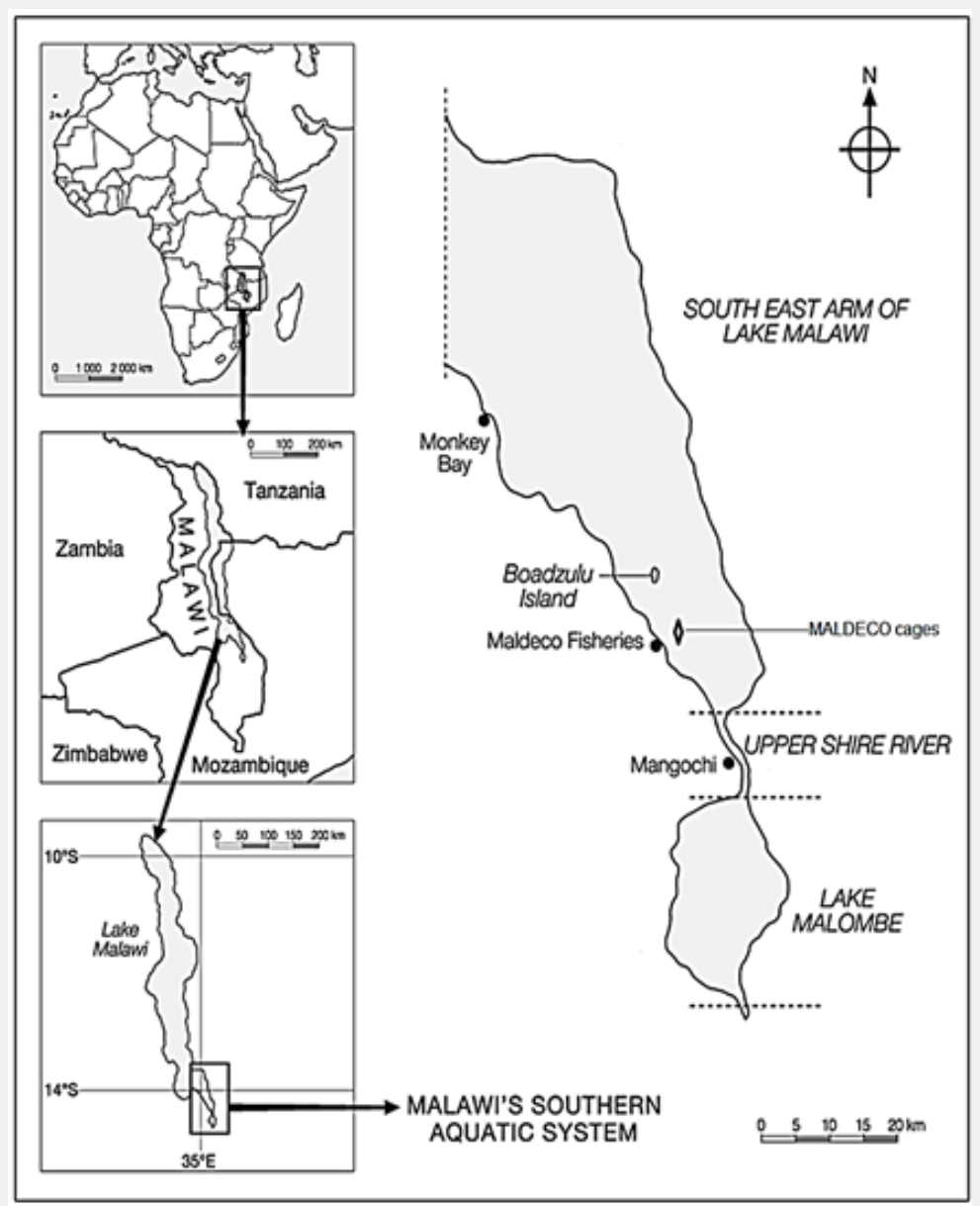

Figure 1: Map of South East Arm of Lake Malawi, Upper Shire River and Lake Malombe showing MALDECO cages (study area). Cages area is not drawn to scale Modified from [7].

\section{Study design}

The study used secondary data collected by MALDECO Aquaculture Limited. Six floating cages of $14.7 \mathrm{~m}$ diameter and approximately $6 \mathrm{~m}$ depth were stocked, each with 105,000
Oreochromis shiranus fingerlings of $1.59 \pm 0.04 \mathrm{~g}$ average body weight (ABW) placed in Lake Malawi. The fish was subjected to two treatments where in $\mathrm{T}_{1}$ fish mortality was estimated using linear method, while in $\mathrm{T}_{2}$ fish mortality was estimated using 
non-linear method. Standing fish biomass was used to calculate approximate feed requirements in each of the respective cages. The treatments were replicated three times, and the fish was cultured for a period of 365 days.

\section{Feeding of experimental fish}

The fish was fed in the morning and afternoon at 9:00hrs and 14:00hrs respectively, with formulated feed of 36\% crude protein (CP) from MALDECO Aquaculture's Feed Milling Section. Feeding rate was adjusted from $4 \%$ of total body weight during the first and second month, to $3 \%$ of total body weight for the third and fourth month, and $2 \%$ of total body weight for the fifth, sixth and seventh month and finally $1 \%$ of total body weight for the remainder of the culture period. Feed was administered by broadcasting and was presented as dry pellets.

\section{Data collection}

MALDECO collected data on fish mortality, weight of fish feed used, fish growth, production costs and fish sales. Data on fish mortality and feed was collected on daily basis, while data on growth and production costs was collected on monthly basis. Data on fish sales was collected at the end of the production cycle. Fish mortality was monitored twice every day during feeding trips and divers were monitoring fish carcasses that sunk to the bottom of the cage once every week. The initial total body weight of the fish $(\mathrm{kg})$ was recorded at the time of stocking, and the fish was sampled to monitor fish growth every last day of the month. Fish growth data was used as a mechanism to dictate adjustments in feeding rates respective of average body weight. To avoid biasness, fish samples were collected by random sampling. Numbers of fish dying were recorded on daily basis throughout the research period and this assisted in adjusting feed requirements in the cages respective of standing biomass. The sampling exercise was conducted early in the morning between $6.00 \mathrm{hrs}$ and $9.00 \mathrm{hrs}$. A seine net was used to seine fish from the cages to get a representative sample, while a scoop net was used to get fish samples from the seined fish which was batch-weighed using a standard weighing scale. A sample size of 500 fish from each cage was used at every sampling interval, and batch weights were used to calculate average body weight. After 365 days of culture, all the fish in the cages was harvested. The fish was counted to calculate total mortality figures, and final body weight was measured to determine fish growth.

\section{Data Analysis}

Growth indices were estimated using the following formulas:

Mean weight gain (MWG)

$$
M W G=W t_{2}-W t_{1}
$$

Where: Wt2 is final mean weight of fish at time t2, Wt1 is initial mean weight of fish at time $t 1$.

Mortality Rate (MR) \%

$$
M R=M \div N \times 100
$$

Where: $\mathrm{M}$ is natural mortality, $\mathrm{N}$ is number of fishes stocked.

Feed Conversion Ratio (FCR)

$F C R=F \div M W G$ 3

Where: F is amount of feed used (g), MWG is Mean Weight Gain.

Economic indicators were calculated using the following: -

Gross Margin (GM)

$G M=T R-T V C$

Where: TR is Total Revenue, TVC is Total Variable Cost.

Return to Variable Cost (RVC)

$R V C=G M \div T V C$ 5

Where: GM is Gross Margin, TVC is Total Variable Cost.

Break-even Yield (BEY)

$B E Y=T V C \div P$. 6

Where: TVC is Total Variable Cost, $\mathrm{P}$ is Price of product (output).

Break-even Price (BEP)

$B E P=T V C \div Y$

Where: TVC is Total Variable Cost, Y is Yield (output).

Data was entered and analysed using Statistical Package for Social Scientists (SPSS) version 16.0. Microsoft (Ms) excel 2007 was used to generate graphs. Hypothesis testing was done by Chi-Square test at $95 \%$ confidence interval.

\section{Results}

\section{Growth performance}

To assess feed efficiency in the two treatments, various production characteristics were calculated using Equations 1-3, and presented in Table 1. Fish growth over the experimental period was not different despite fish being subjected to different treatments in estimation of mortality.

Table 1: Growth of tilapia in weight, and feed used in the two treatments.

\begin{tabular}{|c|c|c|}
\hline Production characteristic & Linear & Non-Linear \\
\hline Mortality & 31500 & 31500 \\
\hline Density & 105000 & 105000 \\
\hline Initial weight (g) & $1.59 \pm 0.04$ & $1.59 \pm 0.04$ \\
\hline ABW (g) & $179.41 \pm 7.71$ & $177.56 \pm 8.27$ \\
\hline MWG (g) & $177.81 \pm 7.71$ & $175.96 \pm 8.51$ \\
\hline Feed used: Makumba & $11644 \pm 4349.77$ & $9186.67 \pm 3574.6$ \\
\hline Grower (kg) & $8756.1 \pm 1593.98$ & $7996.87 \pm 1311.13$ \\
\hline Makumba Finisher (kg) & $1.64 \pm 0.15$ & $1.54 \pm 0.14$ \\
\hline FCR & \multicolumn{2}{|l}{} \\
\hline
\end{tabular}

Values $=$ Mean \pm SE 


\section{Feed Conversion Ratio}

Figure 2 present results of calculated FCRs to evaluate effect of the two treatments on feed efficiency.
Chi-square test results showed that there were significant variations in FCR between linear $(1.64 \pm 0.15)$ and non-linear $(1.54 \pm 0.14), \chi^{2}=0.003$.

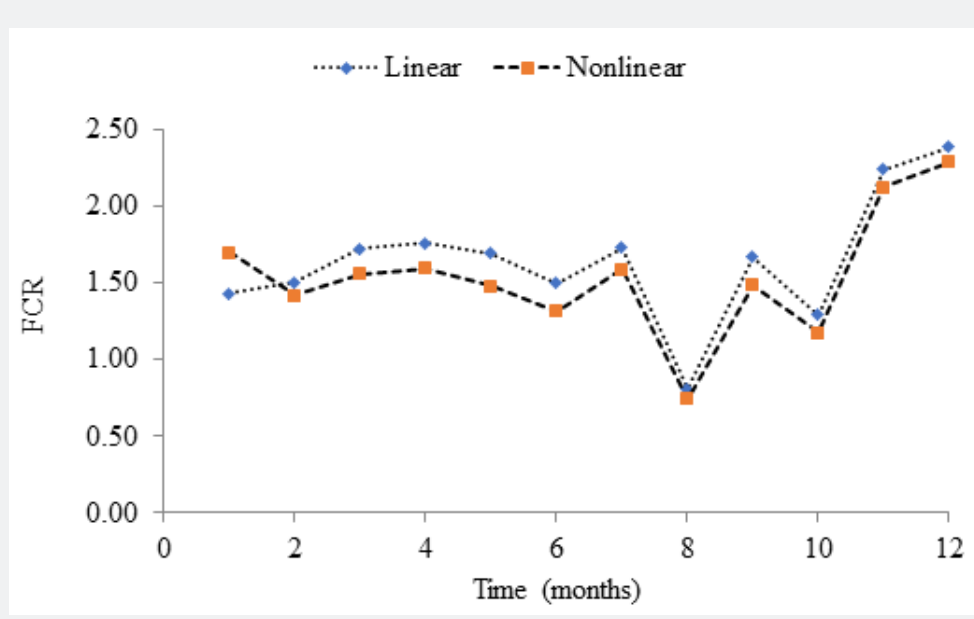

Figure 2 : FCR response to linear and non-linear fish mortality estimation

\section{Profitability}

To assess effect of linear and non-linear estimation of mortality on the profitability of $O$. shiranus, economic performance parameters for the 53 cages were estimated and calculated using Equation 4-7 as presented in Table 2. Profitability analysis results through enterprise budgeting showed that feed for linear treated cages accounted to $77.73 \%$ of total variable costs, while for non-linear cages feed contributed $74.62 \%$ to total variable costs. Linear treatment produced a yield

Table 2: Profitability performance of 53 cages for the two treatments. of $10.47 \mathrm{~kg} / \mathrm{m}^{3}$ and to break even, the harvested biomass needed to exceed $6.54 \mathrm{~kg} / \mathrm{m}^{3}$ for linear, against $5.74 \mathrm{~kg} / \mathrm{m}^{3}$ for nonlinear treated cages which produced a yield of $10.36 \mathrm{~kg} / \mathrm{m}^{3} . \mathrm{T}_{2}$ registered a bigger Gross Margin of MK356,065.29 for a return to total variable cost of $80 \%$ and return to feed of $108 \%$ on a realised revenue of MK799,130,178.09, compared to a Gross Margin of MK302,523,924.30 for a return to total variable cost of $60 \%$, and a return to feed of $77 \%$ on revenues of MK807,532,281.70 for $\mathrm{T}_{1}$. Chi-Square results showed significant effects of linear and nonlinear mortality estimation on gross margin, $z^{2}=0.001$.

\begin{tabular}{|c|c|c|c|c|}
\hline Economic Parameters & Linear & Percent & Non-Linear & Percent \\
\hline Seed cost $(K)$ & $83,475,000$ & 16.51 & $83,475,000$ & 18.82 \\
\hline Feed cost $(\mathrm{K})$ & $392,910,006$ & 77.73 & $330,966,506.40$ & 74.62 \\
\hline Labour cost $(\mathrm{K})$ & $18,640,696$ & 3.69 & $18,640,696$ & 4.2 \\
\hline Transportation cost $(\mathrm{K})$ & $2,834,015.40$ & 0.56 & $2,834,015.40$ & 0.64 \\
\hline Other costs $(\mathrm{K})$ & $7,148,640$ & 1.41 & $7,148,640$ & 1.61 \\
\hline Total Income / Revenue (K) & $807,532,282.70$ & & $799,130,178.09$ & \\
\hline Total variable costs (TVC) (K) & $505,008,357.40$ & & $443,064,857.80$ & \\
\hline Gross margin for 53 cages $(\mathrm{K})$ & $302,523,924.30$ & & $356,065,320.29$ & \\
\hline Return to variable costs & 0.6 & & 0.8 & \\
\hline Return to feed & 0.77 & & 1.08 & \\
\hline Break-even yield (TVC/Price) (kg) & 416251.26 & & 365194.56 & \\
\hline Break-even price (TVC/Yield) (K) & 758.72 & & 672.66 & \\
\hline Return to labour (GM/Total man days) & 16.23 & & 19.1 & \\
\hline
\end{tabular}

\section{Discussion}

\section{Effect of mortality estimation methods on FCR}

Results from effect of mortality estimation methods on FCR showed that there were significant differences between use of linear and non-linear methods $\chi^{2}=0.001$. This demonstrates that mortality estimation methods affect feed conversion ratios of fish in cages. These results suggest that use of non-linear fish mortality estimation methods result into significant changes in the calculated feed conversion ratio in cage cultured $O$. shiranus. Specifically, the results suggest that when adjusting 
fish feed based on non-linear method of estimating fish mortality which on average reduces fish feed by $15.77 \%$, the fish used statistically lower amount of feed to grow $1 \mathrm{~kg}$ of fish muscles. This agrees with [8] who suggested that overfeeding wastes feed and result into higher FCR. The differences in feed between the two treatments, can be attributed to overestimation of biomass during the first three months of culture in linear treated cages where mortality rate was higher in non-linear $(28.37 \%)$ than in linear (7.5\%). This agrees with [9] who also found that FCR is affected by miscalculation of mortality estimates. However, the yielding of lower FCR by non-linear method, as reported by Bhijkajee \& Gobin in [10] suggests efficient food utilization through the extraction of more nutrients from the food and converting it into flesh. The recorded FCR agrees with what was earlier reported that FCR for Tilapia in cages range from 1.4 to 2.5 [9].

\section{Effect of mortality estimation methods on profitability}

The results from effect of mortality estimation methods on profitability showed that there were significant differences between use of linear and non-linear methods $z^{2}=0.001$. This demonstrates that mortality estimation methods affect profitability of fish in cage culture. Use of non-linear estimation of fish mortality ensures that more profits are realized as opposed to the use of linear fish mortality estimation. This can be attributed to differences in feed estimates between the two methods in which non-linear used slightly less feed by $15.77 \%$. The results agree with [8] who suggested that feeding and feed costs represent the single largest component of operating costs and the quality of feed and the way it is used are significant determinants of profitability. The differences in feed between the two treatments can be credited to overestimation of biomass during the first three months of culture in linear treated cages where mortality rate was higher in non-linear $(28.37 \%)$ than in linear (7.5\%). This means that use of linear method overfed the fish by $20.73 \%$ during the period. This result agrees with [11] who reported that accurate, detailed and complete records can help fish farmers to provide control over the business and improve the management and efficiency of the farm, provide a basis for farm credit and financing, determine the relative profitability of various production techniques or systems, and provide information for government programs. Farmers using linear method of estimating fish mortality therefore lose $17.70 \%$ of their potential profits than those using non-linear method of estimating fish mortality, translating into $10.60 \%$ of total operational costs.

\section{Conclusion}

From this study, "the effect of linear and non-linear estimation of mortality on feed conversion rate and profitability of Oreochromis shiranus cultured in cages", which was to investigate on the lack of efficient fish mortality estimation method, it can be suggested that use of non-linear method, has significant effect on feed conversion ratio by yielding lower FCR than linear method. On the objective of assessing profitability calculated based on linear and non-linear mortality estimation methods in cage cultured 0 . shiranus, the study also concludes that non-linear method has significant effect on profitability by yielding more profits than linear method. Therefore, for the attainment of profit-oriented cage culture, farmers must aim at lowering feed conversion ratios and reducing production costs to bring about increased profits by ensuring conscious estimation of fish mortality to reduce miscalculation of feed.

\section{Acknowledgements}

The authors would like to give special thanks to Dr Daniel Jamu (then Aquaculture Manager) and Management and staff of MALDECO Aquaculture Ltd for their support in making the study a success.

\section{References}

1. Harley A (2009) Exploring the possibilities of a sustainable cage culture system in Lake Malawi. Ecological Aquaculture Studies and Reviews. Kingston RI, University of Rhode Island, USA.

2. (2011) World Fish Centre Cage culture in Malawi.

3. Bangladesh Fisheries Society (2011) Effect of stocking density on growth and production performance of tilapia (Oreochromis niloticus $L$.) in ponds.

4. Zydlewski B (2012) Mortality.

5. Auburn University (2002) Fish Mortality Management BMP No. 13 [Internet] Alabama Aquaculture Best Management Practice.

6. Killian HS, Heikes D, Van Wyk P, Masse M, Engle C (1998) Inventory assessment methods for aquaculture ponds. Southern Regional Aquaculture Centre Publication No. 395.

7. Hara M (2006) Restoring the chambo in Southern Malawi: Learning from the past or re-inventing the wheel? Aquatic Ecosystem Health and Management Volume 9(4): 419-432.

8. Beveridge MCM (2004) Cage Aquaculture. ( $3^{\text {rd }}$ edn.), Oxford, Blackwell Publishing Ltd, UK.

9. Ofori JK, Dankwa HR, Brummett R, Abban EK (2009) Producing Tilapia in small cage in West Africa. WorldFish Centre Technical Manual, No. 1952, pp.16, Penang, The WorldFish Centre, Malaysia.

10. Dill A (2010) The effect of stocking density and supplementary feeding on growth performance and yield of Nile tilapia Oreochromis niloticus $(\mathrm{L}, 1758)$ in cage culture in Wonji Reservoir, Ethiopia. MSc thesis, Addis Ababa University School of Graduate Studies, Ethiopia.

11. Pomeroy R (2003) Aquaculture record keeping. Fact sheet, University of Connecticut, US. 
- Quality Editorial service

- Swift Peer Review

- Reprints availability

- E-prints Service

- Manuscript Podcast for convenient understanding

- Global attainment for your research

- Manuscript accessibility in different formats

( Pdf, E-pub, Full Text, Audio)

- Unceasing customer service

Track the below URL for one-step submission https://juniperpublishers.com/online-submission.php 